\title{
Embolization of a duodenal arteriovenous malformation in hereditary hemorrhagic telangiectasia: Case report and review of the literature
}

\author{
Phil Inouye MD MSc ${ }^{1}$, Norman Marcon MD FRCPC ${ }^{2}$, Robin A Pugash MD FRCPC ${ }^{3}$, \\ Robert H Hyland MD FRCPC ${ }^{4}$, Marie E Faughnan MD MSC FRCPC ${ }^{4,5}$
}

\begin{abstract}
P Inouye, N Marcon, RA Pugash, RH Hyland, ME Faughnan. Embolization of a duodenal arteriovenous malformation in hereditary hemorrhagic telangiectasia: Case report and review of the literature. Can J Gastroenterol 2003;17(11):661-665.

A 68-year-old man with hereditary hemorrhagic telangiectasia presented with recurrent, intermittent gastrointestinal hemorrhage. Transfusion of a total of 27 units of red blood cells was required over the three months before admission. Upper and lower endoscopy did not reveal a source of bleeding and a technetium-labelled red blood cell scan was noncontributory. Angiography demonstrated a duodenal arteriovenous malformation originating from a superior mesenteric artery branch. Embolization of the arteriovenous malformation was performed with resolution of gastrointestinal hemorrhage and reduced requirement for blood transfusion. The utility of transcatheter embolization in the management of duodenal arteriovenous malformations in hereditary hemorrhagic telangiectasia is discussed.
\end{abstract}

Key Words: Arteriovenous malformation; Hereditary hemorrhagic telangiectasia; Gastrointestinal hemorrhage

\section{L'embolisation de la malformation artério-} veineuse duodénale en cas de télangiectasie hémorragique héréditaire : Rapport de cas et analyse bibliographique

\begin{abstract}
Un homme de 68 ans atteint d'une télangiectasie hémorragique héréditaire s'est présenté avec une hémorragie gatro-intestinale récurrente et intermittente. On lui avait transfusé un total de 27 unités de globules rouges au cours des trois mois précédent son admission. Une endoscopie supérieure et inférieure n'a pas permis de révéler la source de l'hémorragie, et une scintigraphie des érythrocytes marqués par technétium n'a rien apporté de plus. L'angiographie a révélé une malformation artérioveineuse du duodénum provenant de l'artère mésentérique supérieure. Une embolisation de la malformation artérioveineuse a été effectuée et a permis de résoudre l'hémorragie gastro-intestinale et de réduire les besoins de transfusion sanguine. L'utilité de l'embolisation transcathétérienne dans la prise en charge des malformations artérioveineuses du duodénum en cas de télangiectasie hémorragique héréditaire est abordée.
\end{abstract}

\section{CASE PRESENTATION}

A 68-year-old man with hereditary hemorrhagic telangiectasia (HHT) presented to hospital with recurrent gastrointestinal hemorrhage $(\mathrm{GIH})$, manifesting as intermittent melena, for five years. Previous investigation by esophagogastroduodenoscopy (EGD) revealed four telangiectasias in the stomach that were cauterized. Colonoscopy did not reveal the source of bleeding. The symptoms had progressed, and during the three months before admission to our hospital he had required transfusions of 27 units of packed red blood cells.

Other manifestations of HHT in this patient were moderately severe epistaxis, cutaneous telangiectasias (face, tongue, lips, ear and hands) and bilateral pulmonary arteriovenous malformations (AVMs) for which he had undergone embolization 16 months before the current admission. He also had a history of seizures and transient ischemic attacks; the former were well controlled medically and the latter had resolved after embolization of the pulmonary AVMs. There were no cerebral AVMs. Other past medical history included a left renal oncocytoma, hypertension, right cataract and corneal surgery, and tonsillectomy.

The following investigations were completed to identify a source of the bleeding. A technetium-labelled red blood cell (RBC) scan was noncontributory for a site of blood loss. EGD revealed only small telangiectasias in the posterior wall of the stomach. These were not actively bleeding and not thought to be responsible for the clinical presentation of sudden, large volume GIH in this patient. Hemoglobin concentration was $85 \mathrm{~g} / \mathrm{L}$ on the day of the EGD (normal $130 \mathrm{~g} / \mathrm{L}$ to $170 \mathrm{~g} / \mathrm{L}$ ). Enteroscopy showed no obvious lesions in the duodenum and colonoscopy to the cecum revealed only small diverticulae but no active bleeding and no clear source of recurrent hemorrhage.

Ultrasound investigation of the abdomen identified a mildly inhomogeneous echo texture of the liver and a solid mass in mid pole of the left kidney consistent with a previously known renal oncocytoma. The gallbladder, common bile duct, pancreas, spleen and great vessels were normal. Mesenteric duplex ultrasound demonstrated markedly elevated flow within the

${ }^{1}$ Department of Medicine, University of Toronto; ${ }^{2}$ Division of Gastroenterology, Department of Medicine, St Michael's Hospital, University of Toronto; ${ }^{3}$ Department of Medical Imaging,University of Toronto, Department of Medical Imaging, Sunnybrook and Women's College Health

Sciences Centre; ${ }^{4}$ Division of Respiratory Medicine, Department of Medicine, St Michael's Hospital, University of Toronto; ${ }^{5}$ Financial Support,

Squires Club, Nelson Arthur Hyland Foundation, Sonor Foundation, St Michael's Hospital Research Institute, Toronto, Ontario

Correspondence and reprints: Dr Marie E Faughnan, St Michael's Hospital, 30 Bond Street, Suite 6045, Toronto, Ontario M5B 1 W8.

Telephone 416-864-5516, fax 416-864-5649, e-mail faughnanm@smh.toronto.on.ca

Received for publication February 18, 2003. Accepted August 20, 2003 


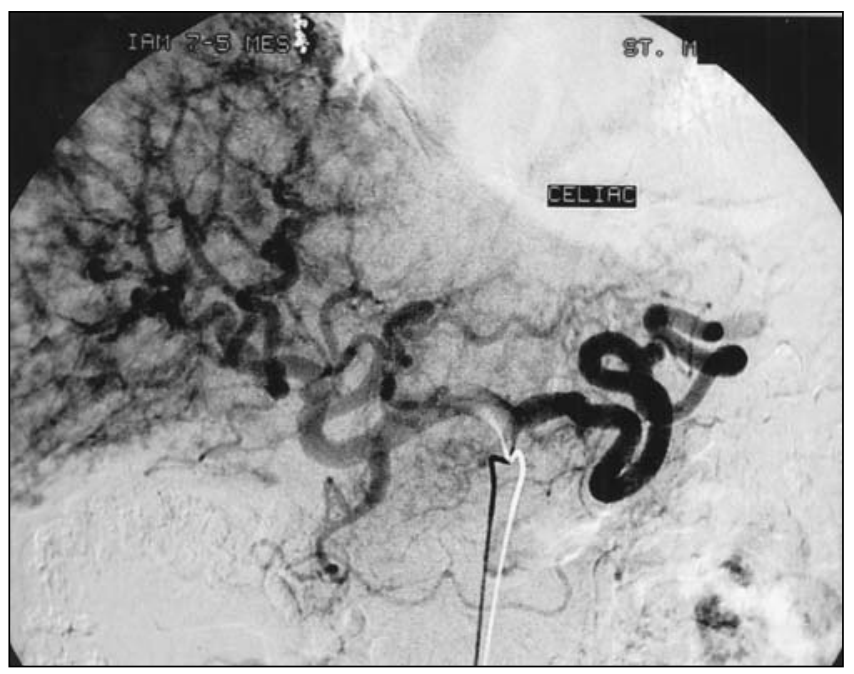

Figure 1) Selective celiac arteriogram shows dilation of main branches. Patchy ill-defined opacities throughout the liver are typical telangiectasias

celiac axis at slightly less than $4 \mathrm{~L} / \mathrm{min}$. Hepatic artery flow was abnormal, but difficult to accurately quantify. There was normal flow in the superior mesenteric artery (SMA) and in the right main and left portal veins.

A mesenteric angiogram was performed from a right retrograde femoral access initially using a flush catheter for an aortogram, and then a 5 French SOS-Omni catheter for selective exams of the celiac, splenic, common hepatic, proper hepatic, gastroduodenal, superior mesenteric and inferior mesenteric arteries. Injection of the SMA showed a small duodenal AVM. Injection of the common hepatic artery showed patchy opacification of all of the hepatic parenchyma, produced by diffuse small telangiectasias with evidence of arterioportal shunting (Figure 1). In addition, there were pancreatic telangiectasias with shunting, and the celiac trunk (Figure 2), common hepatic and splenic arteries were all dilated. No extravasation of contrast, representing active bleeding, was seen by angiography.

The patient underwent superselective arteriography of the SMA to isolate the AVM (Figure 3). Platinum coil embolotherapy was performed, with total occlusion of the vessel feeding the malformation (Figure 4) and resolution of GIH. There were no complications from the procedure. In the following six months there was no history of recurrent $\mathrm{GIH}$; however, the patient required transfusion with six units of $\mathrm{RBCs}$ due to ongoing epistaxis.

\section{DISCUSSION}

HHT (also known as Osler-Weber-Rendu disease) is an autosomal dominant disorder characterized by vascular abnormalities, as recently reviewed $(1,2)$. There are two types of vascular lesions in HHT. The first type is the mucocutaneous telangiectasia. Telangiectasias are small focal dilations of capillaries and postcapillary venules within the mucosa resulting in direct connections between arterioles and venules. When these lesions are found within the gastrointestinal tract they may be termed angiodysplasia. The second type of lesion is the visceral AVM. AVMs are direct connections between arteries and veins that lack intervening capillaries and are larger than telangiectasias or angiodysplasia. In patients with HHT, telangiectasias and/or AVMs may be found in the lungs, brain,

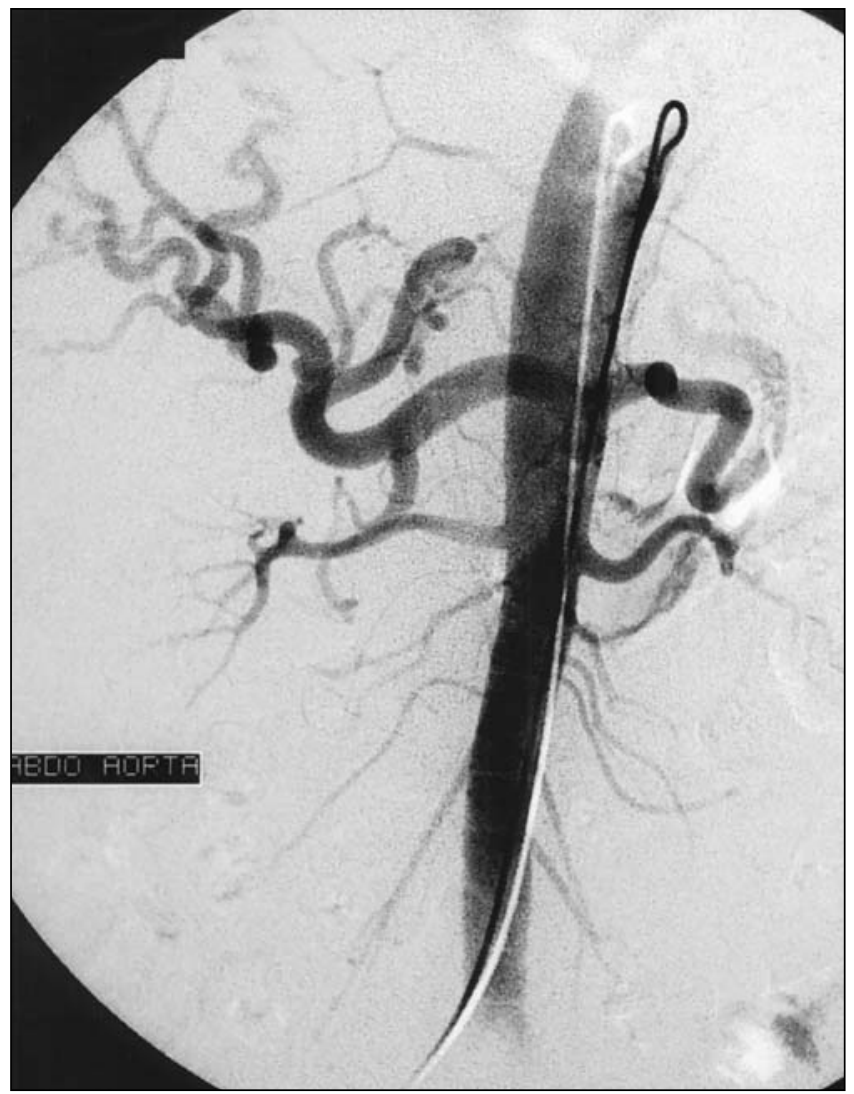

Figure 2) Abdominal aortogram shows dilation of the aorta to the level of the celiac trunk (secondary to high flow through celiac territory). The celiac trunk and its branches are all massively dilated

skin, nose, liver and pancreas, as well as throughout the gastrointestinal tract.

Telangiectasias occur in the gastrointestinal tract in about $60 \%$ of patients with HHT; AVMs are less common. GIH occurs in $10 \%$ to $45 \%$ of patients with HHT, commonly originating from telangiectasias and presenting as iron deficiency anemia. Less commonly, HHT patients will have bleeding from AVMs, presenting with sudden, massive hemorrhage $(3,4)$. In a retrospective case series of 28 patients with HHT and $\mathrm{GIH}, 40 \%$ of patients presented with an upper $\mathrm{GIH}, 10 \%$ with a lower GIH and in 50\% the bleeding site was indeterminate. EGD was performed on 17 of these patients, and while $70 \%$ had typical lesions in the stomach, no duodenal lesions were described (5). Duodenal telangiectasias in HHT have been reported by other authors (6-11). There is only one report (12) describing a duodenal AVM in a patient who may have had HHT, based on a family history of a brother with recurrent $\mathrm{GIH}$ attributed to congenital telangiectasias. In non-HHT patients, angiodysplastic lesions are also more commonly reported than AVMs in the duodenum (13-16). In one review of 218 patients with bowel AVMs, only five patients were found to have lesions in the duodenum (17).

Diagnosis of gastrointestinal lesions in HHT can be made by endoscopy, angiography, technetium radionucleotide scan or laparotomy. Telangiectasias are usually easy to identify by endoscopy (9) but they may be difficult to see in patients with profound anemia (18). Clinically important submucosal AVMs may not be recognized unless they are actively bleeding at the 


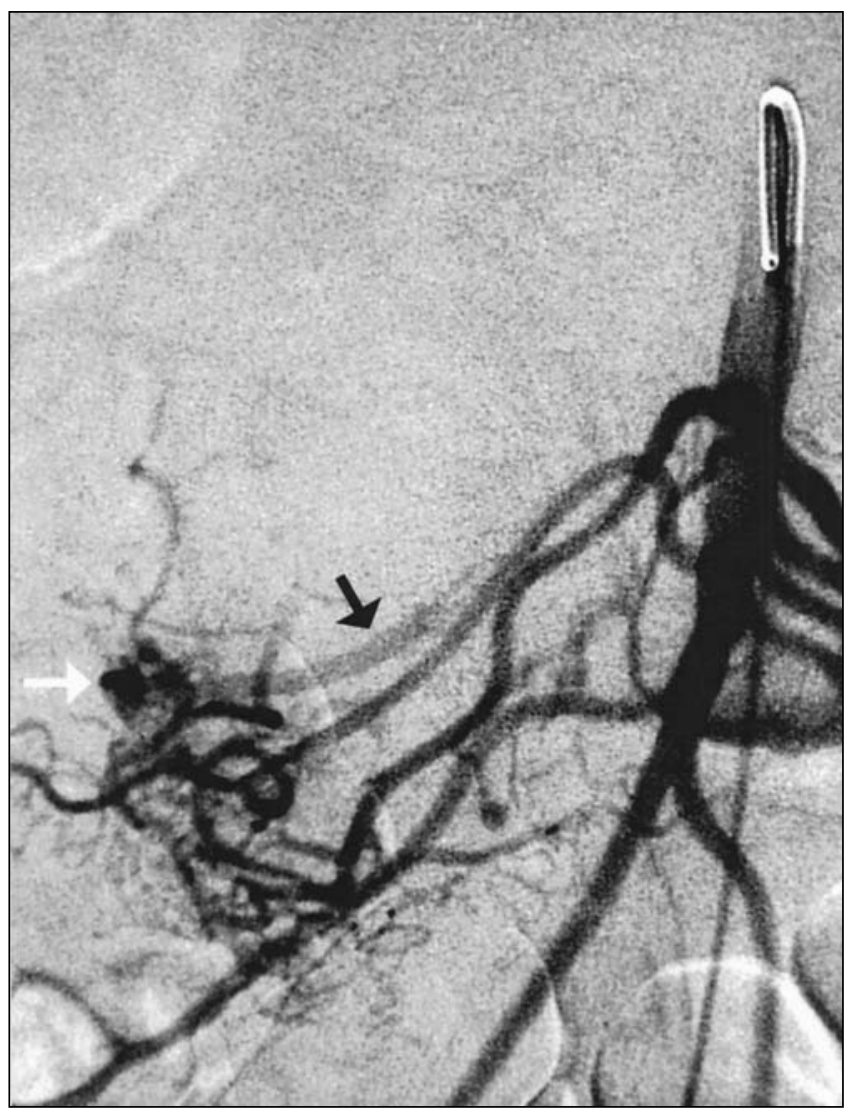

Figure 3) Selective superior mesenteric arteriogram shows tortuous vessels plus small aneurysms (white arrow) in inferior pancreaticoduodenal territory. The black arrow points to the draining vein of this arteriovenous malformation

time of endoscopy. Furthermore, the yield may be influenced by the type of endoscopic device used. Traditional end-viewing esophagogastroduodenoscopes (at a length of $110 \mathrm{~cm}$ ) allow visualization to the distal duodenum, to see beyond that, commercially available enteroscopes $(200 \mathrm{~cm}$ to $250 \mathrm{~cm}$ ) may be passed with or without an overtube $(19,20)$. In certain cases a side-viewing duodenoscope would be optimal.

Endoscopy is often the initial procedure for treating bowel lesions in patients with HHT. Telangiectasias can be treated by endoscopic thermocoagulation with either bipolar, laser (potassium titanyl phosphate or neodymium:yttriumaluminum-garnet) or noncontact with argon plasma coagulation $(21,22)$. In patients with HHT, heater probe, bipolar electrocoagulation and laser have comparable results in controlling acute bleeds from telangiectasias (23).

Medical therapy has a role in the management of GIH in some patients with HHT. Estrogen combined with progesterone has been shown to reduce the transfusion need in patients with bleeding malformations in the gastrointestinal tract, including six patients with HHT (24). However, estrogen can be poorly tolerated in men (6). Case reports of using aminocaproic acid have shown conflicting results in reducing the number of blood transfusions required in patients with HHT (25-27). Surgical management may be required in some patients with HHT to prevent ongoing GIH in refractory cases and in patients with larger AVMs thought to be less amenable to medical therapy or endoscopic management.

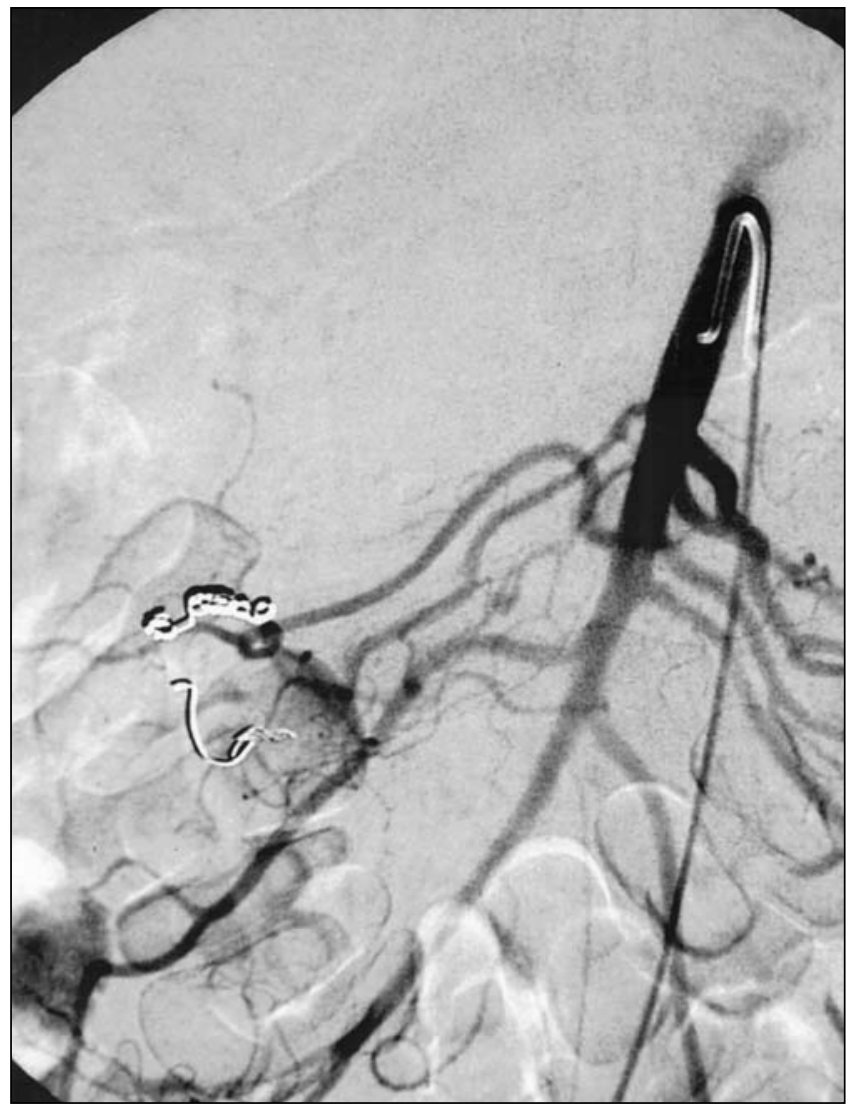

Figure 4) The superior mesenteric anteriogram performed following coil embolotherapy shows no flow through the arteriovenous malformation

Visceral arteriography and embolotherapy have been shown to be effective for the diagnosis and treatment of GIH in nonHHT patients $(28,29)$. The site of hemorrhage can be identified by the location of intraluminal extravasation of contrast material or direct identification of vascular malformations. GIH can then be controlled by the selective infusion of vasoconstrictive drugs such as vasopressin, or by selective embolization with coils, polyvinyl alcohol particles, gelatin sponge or tissue adhesive $(30,31)$.

Potential complications of embolotherapy include those related to angiography (groin hematoma, femoral artery injury or thrombosis, embolism, contrast reactions such as anaphylaxis, and contrast-associated renal failure) or those caused by embolization itself (bowel wall ischemia and infarction). Embolization of nontarget organs is possible but unlikely in the hands of experienced interventional radiologists. Superselective embolization is crucial in minimizing the likelihood of gut ischemia, but may be technically quite challenging. In a series of 40 patients reported by Defreyne et al (29), no bowel complications occurred; however, one partial liver lobe and one partial spleen infarction were noted.

There are no reports of small bowel AVMs treated by embolization in patients with HHT; however, there have been reports in non-HHT patients. In patients undergoing embolization for acute nonvariceal $\mathrm{GIH}$, the bleeding lesion was devascularized by embolization in 39 of 40 patients (29). The most common source of bleeding in these patients were ulcers. In one non-HHT patient, a jejunal AVM was the source 
of bleeding and showed intermittent contrast medium extravasation during angiography (28). The jejunal artery was embolized with polyvinyl alcohol and the patient was asymptomatic for four months. However, when melena recurred, angiography was used to demonstrate revascularization of the previously embolized lesion. The microcatheter was then used for methylene blue marking to direct laproscopic resection of the involved jejunum and the patient was free of symptoms at 18 months.

Poon and Poon (16) described a duodenal AVM in a patient who did not have HHT. This lesion was embolized using Gelfoam absorbable gelatin sponge (Pharmacia \& Upjohn, USA); however, the lesion continued to bleed and the patient underwent laparotomy and ligation of the gastroduodenal artery. In a review of patients who underwent transcatheter embolic occlusion of the gastroduodenal artery for treatment of duodenal bleeding, Granmayeh et al (32) described one patient who had a vascular abnormality as the cause of GIH. Occlusion with wire coils successfully controlled bleeding in this patient for one year. The patient later re-bled and was successfully treated with occlusion of collaterals. Furthermore, Palmaz et al (31) described two patients with small bowel AVMs who were successfully treated with selective embolization of jejunal and ileal arteries.

When embolization fails to control GIH, angiography can guide surgical resection of the appropriate segment of bowel $(12,14)$. However, the use of angiography has also been reported to misdirect surgical resection, leading to the removal of nor-

\section{REFERENCES}

1. Guttmacher AE, Marchuk DA, White RI. Hereditary hemorrhagic telangiectasia. N Eng J Med 1995;333:918-24.

2. Shovlin CL, Guttmacher AE, Buscarini E, et al. Diagnostic criteria for hereditary hemorrhagic telangiectasia (Rendu-Osler-Weber syndrome). Am J Med Genet 2000;91:66-7.

3. Halpern M, Turner AF, Citron BP. Hereditary hemorrhagic telangiectasia. An angiographic study of abdominal visceral angiodysplasias associated with gastrointestinal hemorrhage. Radiology 1968;90:1143-9.

4. Kjeldsen AD, Kjeldsen J. Gastrointestinal bleeding in patients with hereditary hemorrhagic telangiectasia. Am J Gastroenterol 2000;95:415-8.

5. Reilly PJ, Nostrant TT. Clinical manifestations of hereditary hemorrhagic telangiectasia. Am J Gastroenterol 1984;79:363-7.

6. Moore JD, Thompson NW, Appelman HD, Foley D. Arteriovenous malformations of the gastrointestinal tract. Arch Surg 1976;111:381-9.

7. Owen WJ, McColl I. Hereditary hemorrhagic telangiectasia: Major recurrent gastric bleeding treated by gastrectomy. J R Soc Med 1979;72:937-9.

8. Mayer IE, Hersh T. Endoscopic diagnosis of hereditary hemorrhagic telangiectasia. J Clin Gastroenterol 1981;3:361-5.

9. Vase P, Grove O. Gastrointestinal lesions in hereditary hemorrhagic telangiectasia. Gastroenterology 1986;91:1079-83.

10. Kristoffersson A, Domellof L, Kullenberg K. Gastrointestinal manifestations of hereditary haemorrhagic telangiectasia. Ann Chir Gynaecol 1987;76:96-8.

11. Longacre AV, Gross CP, Gallitelli M, Henderson KJ, White RI, Proctor DD. Diagnosis and management of gastrointestinal bleeding in patients with hereditary hemorrhagic telangiectasia. Am J Gastroenterol 2003;98:59-65.

12. Stallwood GR, Richards TA. Arteriovenous malformation of the duodenum. Can J Surg 1980;23:572-4.

13. Fowler DL, Fortin D, Wood WG, Pinkerton JA, Koontz PG. Intestinal vascular malformations. Surgery 1979;86:377-85.

14. Goldin AR, Dent DM, Davies PG. Angiography in the diagnosis and management of duodenal arteriovenous malformations. S Afr Med J 1979;55:347-8.

15. Criado FJ, Shureih SF, Howard WHB, Wilson TH Jr. Arterio venous malformations of the duodenum: A report of three cases. MD State Med J 1982;31:63-5. mal bowel (15). Catheter injection of methylene blue can be useful to stain involved regions of bowel for resection. Refractory cases in HHT and non-HHT patients often require eventual surgical management $(6-8,12,16,33,34)$.

In the present patient, endoscopic treatment was not possible because the culprit lesion was not identified from within the lumen of the bowel. This is most likely due to the submucosal location of the lesion, anemia and the absence of active bleeding during investigation. In light of the nature of the lesion identified by angiography, medical therapy would not have been appropriate and did not offer a definitive solution. Furthermore, estrogen-progesterone was considered unacceptable to this patient due to the potential adverse effects. Surgery, although a potentially definitive therapy, is far more invasive than transcatheter embolization.

\section{CONCLUSIONS}

In this patient with a single AVM as the source of recurrent GIH, embolotherapy offered a relatively noninvasive and potentially permanent treatment. Embolization is used for treatment of pulmonary and cerebral AVMs in HHT patients (1); however, to our knowledge, this is the first report of a successful embolization of a duodenal AVM in a patient with HHT. Diagnostic angiography should be considered in HHT patients with sudden, massive or refractory GIH and embolization should be considered in the management of AVMs within the duodenum.

16. Poon RT-P, Poon J. Massive GI bleeding due to a duodenal arteriovenous malformation. Gastrointest Endosc 2000;52:101-4.

17. Meyer CT, Troncale FJ, Galloway S, Sheahan DG. Arteriovenous malformations of the bowel: An analysis of 22 cases and a review of the literature. Medicine 1981;60:36-48.

18. Marwick T, Kerlin P. Angiodysplasia of the upper gastrointestinal tract. J Clin Gastroenterol 1986;8:404-7.

19. Taylor ACF, Chen RYM, Desmond PV. Use of an overtube for enteroscopy - Does it increase depth of insertion? A prospective study of enteroscopy with and without an overtube. Endoscopy 2001;33:227-30.

20. Benz C, Jakobs R, Riemann JF. Do we need the overtube for pushenteroscopy? Endoscopy 2001;33:658-61.

21. Naveau S, Aubert A, Poynard T, Chaput JC. Long-term results of treatment of vascular malformations of the gastrointestinal tract by neodymium YAG laser photocoagulation. Dig Dis Sci 1990;35:821-6.

22. Sargeant IR, Loizou LA, Rampton D, Tulloch, Bown SG. Laser ablation of upper gastrointestinal vascular ectasias: Long term results. Gut 1993;34:470-5.

23. Gostout CJ, Bowyer BA, Ahlquist DA, Viggiano TR, Balm RK. Mucosal vascular malformations of the gastrointestinal tract: Clinical observations and results of endoscopic Neodymium: Yttrium-Aluminum-Garnet laser therapy. Mayo Clin Proc 1988;63:993-1003.

24. Van Cutsem E, Rutgeerts P, Vantrappen G. Treatment of bleeding gastrointestinal vascular malformations with oestrogenprogesterone. Lancet 1990;335:953-5.

25. Saba HI, Morelli GA, Logrono LA. Brief report: Treatment of bleeding in hereditary hemorrhagic telangiectasia with aminocaproic acid. N Eng J Med 1994;330:1789-90.

26. Korzenik JR, Topazian MD, White R. Treatment of bleeding in hereditary hemorrhagic telangiectasia with aminocaproic acid. N Eng J Med 1994;331:1236.

27. Annichino-Bizzacchi JM, Facchini RM, Torresan MZ, Arruda VR. Hereditary hemorrhagic telangiectasia response to aminocaproic acid treatment. Thromb Res 1999;96:73-6.

28. Defreyne L, Verstraeten V, De Potter C, Pattyn P, De Vos M, Kunnen M. Jejunal arteriovenous malformation, diagnosed by angiography and treated by embolization and catheter-guided 
surgery: Case report and review of literature. Abdom Imaging 1998;23:127-31.

29. Defreyne L, Vanlangenhove P, De Vos M, et al. Embolization as a first approach with endoscopically unmanageable acute nonvariceal gastrointestinal hemorrhage. Radiology 2001;218:739-48.

30. Aina R, Oliva VL, Therasse E, et al. Arterial embolotherapy for upper gastrointestinal hemorrhage: Outcome assessment. J Vasc Intervent Radiol 2001;12:195-200.
31. Palmaz JC, Walter JF, Cho KJ. Therapeutic embolization of the small-bowel arteries. Radiology 1984;152:377-82.

32. Granmayeh M, Wallace S, Schwarten D. Transcatheter occlusion of the gastroduodenal artery. Radiology 1979;131:59-64.

33. Bruusgaard A, Juhl E. Hereditary hemorrhagic telangiectasis (Rendu-Weber-Osler's disease) with intestinal involvement successfully treated by surgery. Gastroenterology 1974;67:1001-5.

34. Lewis JW, Mason EE, Jochimsen PR. Vascular malformations of the stomach and duodenum. Surg Gynecol Obstet 1981;153:225-8. 


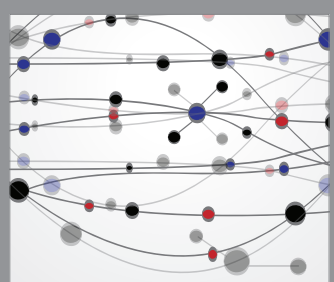

The Scientific World Journal
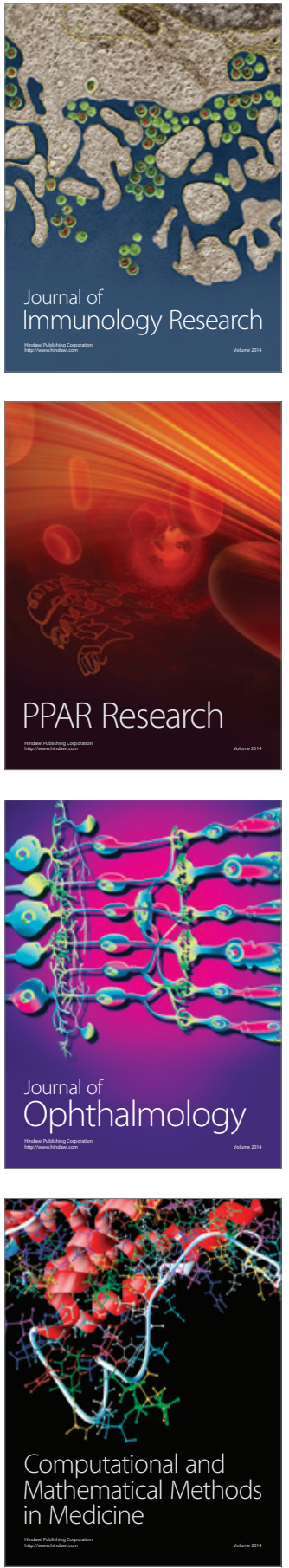

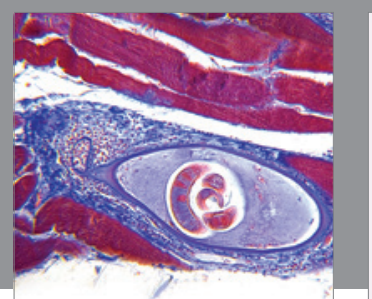

Gastroenterology Research and Practice

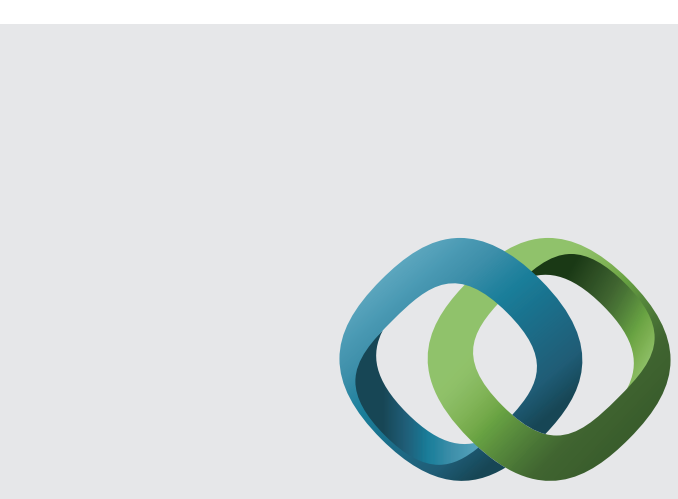

\section{Hindawi}

Submit your manuscripts at

http://www.hindawi.com
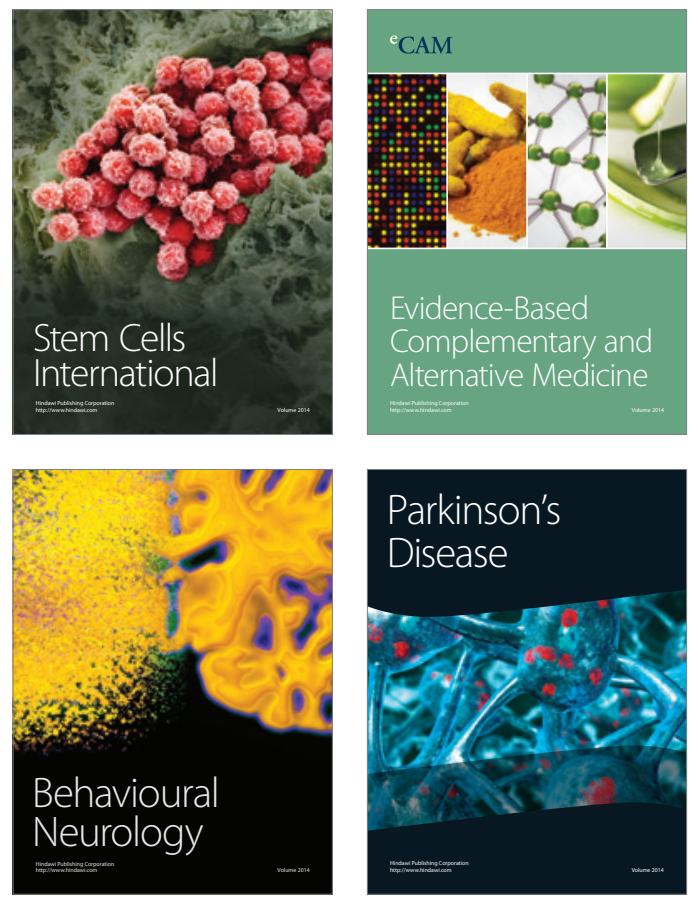
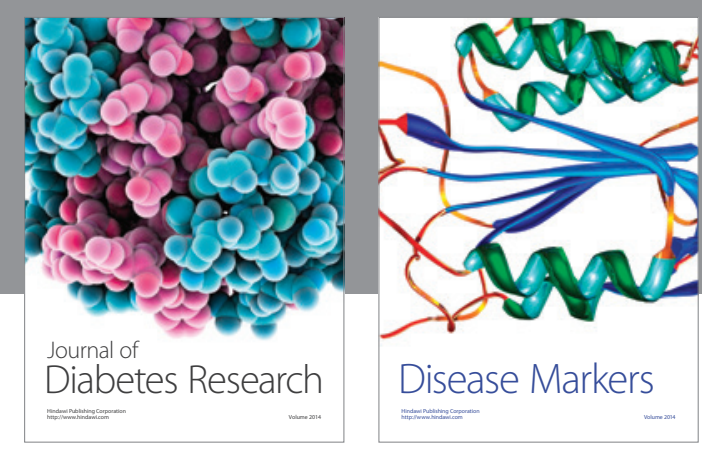

Disease Markers
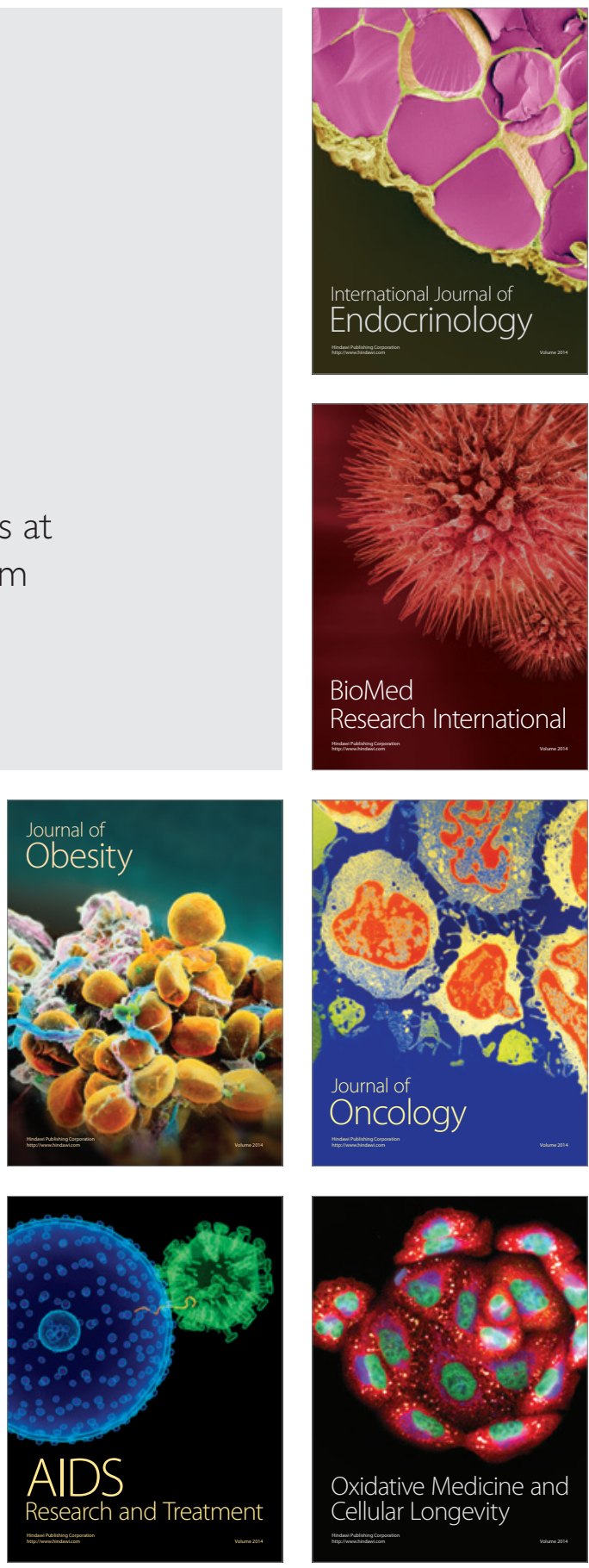